\title{
Doing business in China and India: A comparative approach
}

\author{
(Diego Quer, Enrique Claver and Laura Rienda)
}

\begin{abstract}
Purpose In recent years, China and India have been experiencing a process of economic and social transformation that is unprecedented in recent human history. The consequences of the spectacular resurgence of these two Asian giants are profound and far-reaching, and are causing the centre of gravity of the world economy to be drawn inexorably towards these countries. The aim of this paper is to offer a comparative approach to the reality of China and India as regards business and strategic management.
\end{abstract}

Design/methodology/approach This paper reviews previous literature that has focused on comparing various issues related to business and management in China and India.

Findings We highlight the points of convergence and divergence in the developmental patterns of China and India, the key factors for success in each country, the entry modes that could be used and the business opportunities they offer.

Originality/value This paper provides a comparison between China and India with regard to business and strategic management, analysing the main similarities and differences between the two Asian giants.

Keywords China, India, business and management.

Paper type Viewpoint.

\section{Introduction}

One of the most outstanding events of the late $20^{\text {th }}$ and early $21^{\text {st }}$ century is the sudden emergence of China and India as leading players on the global scene. China is the most heavily populated country on the planet (with over 1,300 million inhabitants), followed by India in second place (with some 1,100 million), meaning that between them they account for around $40 \%$ of the world's population. They are also the second and fourth world economies in terms of purchasing 
power parity, with recent years seeing GDP annual growth rates of over $10 \%$ in China and $9 \%$ in India. The global consequences of this spectacular boom in these two countries are profound and far-reaching and affect not only the products markets but also flows of savings, investments and people, as well as natural resources and the environment (Winters and Yusuf, 2006).

However, rather than talking of the emergence of these two Asian giants, we should be speaking of a resurgence, as they both share a past as two of the most prosperous nations on earth (Kalish, 2006). Long before the emergence of Europe, China and India already had much higher standards of living and many more scientific and technical inventions. Both India and China have contributed greatly to the evolution of humanity (Bhasin, 2007): the Indians domesticated the cow and introduced wheat, barley, cucumbers, sesame, citrus fruits, cotton and flax. The Chinese, on the other hand, domesticated the dog, the pig and the chicken and introduced rice, apricots, peaches and tea. The Chinese also discovered paper, gunpowder, the compass and porcelain. The three great Asian religions (Jainism, Hinduism and Buddhism) originated in India, as did the discovery of the number zero, chess, astronomy, astrology and dye, while China's religious and philosophical contributions include Taoism, Confucianism and the development of Buddhism.

However, as of the early $19^{\text {th }}$ century both countries suffered a long decline and were eclipsed by Europe and the US. By the mid $20^{\text {th }}$ century they were subject to high levels of poverty. The change of fortune in China began in 1978 when Deng Xiaoping came to power and implemented market-oriented economic policies, while in India that change began in the early 1990s when, in response to a financial crisis, the government started taking gradual steps along a market-oriented path.

Both of these countries - and China in particular - have received a great deal of attention in the literature concerning business and management of international companies, but they have received this attention separately and thus comparisons between the two have been scarce. For this very reason, this paper aims to provide a comparative approach to the reality of China and India as regards business and strategic management. Following this introduction, we will outline the main 
points of convergence and divergence in the development policies adopted in recent years, after which we will examine the key factors for success in each country, with a particular focus on negotiating with Chinese and Indian companies and on the attraction of these destinations for foreign investment. We will then compare the various entry modes that could be used within the existing legal framework, before taking an in-depth look at the main business opportunities available to foreign firms. Finally, we will outline the future challenges posed by the reawakening of these two Asian giants.

\section{Similarities and differences between the dragon and the elephant}

\subsection{Institutional, political and legislative framework}

The first point of convergence between the two countries can be found in the fact that their economic boom was preceded by a series of political changes (Huang, 2008): the Chinese miracle began in the 1980s, when policy became more open and less authoritarian with the introduction of various measures such as the creation of an environment more favourable to private property; India's growth, meanwhile, accelerated in the 1990s as the nation privatised television stations, introduced political decentralisation and improved governance.

Yet it is within the political systems themselves that we will find one of the main differences, with China's single-party system (Communist Party) contrasting with India's democratic system (in fact, India has been referred to as "the largest democracy in the world" on numerous occasions). In theory, this offers India several comparative advantages (Nobrega, 2008). Despite the slowness of its courts, India's legal system offers greater property rights, while China is reputed to be a haven for the piracy of intellectual property, and business is fundamentally conducted through relationships and interpersonal connections - a cultural construct known as guanxi (Adams, 2007).

Nevertheless, these differences regarding the existing regulatory framework encompass a series of nuances (Kalish, 2006). Although both countries have reduced tariffs and other trade 
barriers, liberalisation has been greater in China thus far. China has recently lifted restrictions on retail trade and is undertaking huge investments to modernise the sector. This is not the case in India, where foreign investment encounters greater restrictions and the retail sector is highly fragmented with inefficient distribution. Also, the various States that make up India enjoy a lot of powers; a fact that translates into highly complex indirect taxation and a slowing down due to internal borders.

In any case, the bursting of emerging economies such as China and India onto the global scene has given greater relevance to the institutional perspective as a third factor determining international success, alongside sectorial conditions and business factors (Peng et al., 2008). For example, in the case of India, why exactly has it become the world's nerve centre for the information and communication technology (ICT) industry, which has now been re-baptised as business process outsourcing? The two traditional explanations are based on the perspective of industry (such activities can be performed "remotely") and on the perspective of resources (Indian companies combine low costs and excellent skills). Although both explanations are valid, they need to be complemented by an institutional perspective centred on the political, legal and social changes of its institutions: decisions by the Indian government to invest in higher education, legal reforms that have liberalised the country's economy, and a favourable domestic and international environment have enabled Indian companies within the sector to flourish.

In the case of China, its spectacular economic growth over the past three decades and the relatively minor development of its formal institutions (such as the lack of effective courts) have raised the following question: how can China be enjoying such rapid growth rates while maintaining its institutional order? One partial response suggests that the interpersonal networks (guanxi) cultivated by executives could serve as an informal substitute for formal institutional support. But it leaves one wondering about the long-term evolution of the importance of these networks of relationships. On the one hand, if it is the national Chinese culture that mainly determines strategic choices, the major dependence on interpersonal relationships will continue to 
be important regardless of any reforms. On the other hand, if it is the minor institutional development that determines strategic choices, there is likely to be a gradual diminishing of the role of interpersonal relationships and a greater dependence on market-based capabilities as the formal support institutions develop ${ }^{1}$.

\subsection{Economic development model}

The fact that China began to implement its reform policies and to open up before India did has meant that it has enjoyed several years' head start in terms of economic liberalisation. China is much further ahead with regard to economic development, level of technology, infrastructures, production capacity and quality of life. The Indian economy continues to be smaller than the Chinese economy and has a smaller impact on the global economy. Chinese exports are eight times greater than Indian exports (WTO, 2008) and foreign direct investment (FDI) in China almost four times that in India (UNCTAD, 2008).

Yet why has the Chinese economy grown faster than the Indian economy? Experts have offered various reasons (Kalish, 2006): Chinese authoritarianism, which has allowed the government to quickly make unpopular decisions that would be more difficult and time-consuming in democratic India; the tightly regulated Indian environment and the aversion to foreign capital, which means less FDI in India as compared to in the more open environment of China; and the superior Chinese infrastructures, which permit more efficient and sophisticated investments than in India $^{2}$.

Although all of these explanations contain an element of truth, they do not tell the whole story. For example, China's economic boom happened in the early 1980s, before investments were made in infrastructures and before China opened up to the global economy. Furthermore, while India might have severe restrictions, its capital markets are more efficient than the Chinese. In fact, Indian entrepreneurs probably have greater opportunities to obtain capital from local banks than their Chinese counterparts. Finally, democracy cannot be considered an obstacle to growth in 
today's information society: on the contrary - the free flow of information constitutes an economic advantage.

In any case, the paths to prosperity taken by the Indian "elephant" and the Chinese "dragon" have been different (Meredith, 2007). One differentiating feature of the Indian model has been the leading role of the service sector as an engine for growth, particularly in the field of ICT (Zaballa, 2006). One of the factors behind this has been the high availability of qualified human capital, resulting from a clearly elitist concept of education that has seen university education favoured over primary education and in which a positive decision has been made to develop English ${ }^{3}$.

The success of China, on the other hand, has been founded on the high volume of manufactured exports (Kalish, 2006). This is partly a legacy of communism, which promoted industrial output and did not recognise the value of services, and it is also a consequence of the huge volume of FDI received, which has been ploughed into large-scale manufacturing plants. In India, the production of goods is relatively lower than international averages due, in part, to the legacy of regulations that discouraged economies of scale in manufacturing. Nevertheless, it must be stressed that, nowadays, China not only specialises in textiles, clothing, toys, and footwear: in recent years it has also increased its overseas sales of advanced electronic and telecommunications products (Bustelo, 2008).

The internal or external orientation of growth is another of the aspects that allow differences in the development paths to be highlighted (Zaballa, 2006). China's growth has been characterised by a high level of family savings that has restricted internal consumption and forced a solution to be sought in exports, thus generating an enormous surplus in the current account. In short, China has followed a traditional model of outward growth. This has not been the case for India, where rates of saving are approximately half those recorded in China, making for more modest results overseas and thus increasing the role played by domestic demand in the country's growth.

Closely related to the above is another of the differentiating aspects of the two countries' development paths: the key role played by FDI in driving economic growth in China (Zheng, 2009). 
India has adopted an import substitution policy that is more inward-facing and very much based on domestic firms and resources. China, on the other hand, has created more opportunities for foreign investors with regard to access to the export markets, in line with the model followed by other Southeast Asian countries. Also, a high proportion of the FDI received by China comes from the overseas Chinese in Hong Kong, Macao, Taiwan and Singapore. The Indian diaspora has not had the same effect on the FDI received in the country, although it has made major contributions in terms of intellectual capital (Bhasin, 2007).

In any case, despite China clearly demonstrating a greater capacity than India for attracting FDI, such a comparison must take account of the difference in calculation methods: Chinese statistics tend to overestimate the amount of FDI received, particularly in terms of round tripping (Chinese companies transferring resources to neighbouring countries such as Taiwan, Hong Kong and Macao, which are subsequently reinvested in China in the form of FDI in order to benefit from the preferential treatment - fundamentally fiscal - applied to this foreign flow). Indian statistics, meanwhile, tend to underestimate FDI by excluding the reinvestment of profits generated by subsidiaries of overseas companies or capital acquired through means other than contributions in cash.

Another differentiating trait within the Indian model of growth is the indirect role played by the public sector in economic growth, lacking as it does the means to play a greater role and lead this growth (Zaballa, 2006). Thus the real protagonist is the private sector. The Indian administration has limited itself to establishing general, overall fiscal and financial conditions without getting involved in the market process for allocating resources: without, in short, playing the executive role it has played in the Chinese model of growth.

Company make-up also presents a differentiating trait. Huge conglomerates of local capital are very much present in the Indian economy, and many of these are family run. This could provide foreign family-run companies with an advantage when dealing with local businesses with similar concerns. However, the family-based nature of many Indian companies can also provoke a 
reluctance in the owner-managers to relinquish control, thereby restricting external investors to minority shareholdings in the capital (Adams, 2007). The Indian environment is more favourable for entrepreneurs. Although a great deal more capital is available in China thanks to its high savings rate, much of this is in the hands of state-owned institutions, meaning that often small businesses cannot access the funds they require (Kalish, 2006).

Finally, another factor that may soon determine economic development in both countries is their demographic structure. The one-child policy in China will mean that, by the mid $21^{\text {st }}$ century, the largest age group within the population will be the 55-65 year olds, leaving many pensioners dependent upon a decreasing workforce (Adams, 2007). The population is younger in India and continues to grow. In the coming years this could be an advantage for India, due to the greater number of people of working age (Kalish, 2006).

\section{Keys to business success in China and India}

\subsection{China and India as destinations for FDI}

Both China and India are unarguably among the preferred countries for international business. This can be confirmed by various studies recently carried out by renowned consulting firms based on surveys of executives at international companies (Ernst \& Young, 2008; KPMG, 2008; PriceWaterhouseCoopers, 2008). Meanwhile Zheng (2009) has compared the determinants of inward FDI in China and India, offering the following results:

- Decisive factors for inward FDI in both countries: market growth; lower labour costs; policy liberalisation; and the amount of exports from China and India to each country of origin of the FDI.

- Factors decisive only for inward FDI in China, and not in India: greater size of the Chinese market and China's strategic location in terms of geography and logistics; greater borrowing 
costs in China relative to the home country (making FDI more cost competitive than local capital); and the amount of China's imports from each home country.

- Factors decisive only for inward FDI in India, and not in China: geographical and cultural distance (the greater geographical distance discourages FDI in India, while the closer cultural distance encourages it).

As regards the last factor, some Western companies are reluctant to invest in China due to the difficulties caused by cultural differences, the language, unfair competition or legal coverage. In contrast, three centuries of British presence in India has given rise to a business culture, administrative organisation and judicial system with which Western companies may be more familiar and, of course, has led to a knowledge of English in a broad sector of the population.

\subsection{Cultural differences: keys to negotiation}

The Chinese can boast that, as a nation, they have shared a common culture over a longer period of time than any other civilisation. Their technological, artistic and intellectual advances have meant they regard their country as a self-sufficient centre of the universe. In fact, their name for China - zhong guo - means "the middle country". The history of India, meanwhile, is littered with numerous invasions and colonisations: the Persians (543 AD), the Greeks (326 AD), the Arabs $\left(10^{\text {th }}-15^{\text {th }}\right.$ centuries), the Portuguese $\left(16^{\text {th }}\right.$ century) and the British (from the $18^{\text {th }}$ to the mid $20^{\text {th }}$ century).

The ancient history of both civilisations has gradually shaped the culture we can encounter today. At first glance, the main cultural differences between China and India can be reduced to the following aspects (Bhasin, 2007):

- Ethnic origin and language. Chinese culture has evolved independently of foreign influences and is more homogenous than Indian culture. The han ethnic group represents 95\% of the Chinese population and is the largest ethnic group in the world. Chinese is also the oldest writing system on the planet, having been in use, with its various developments, 
for over 3,500 years. Although there are varieties of spoken dialects, the main one is Mandarin, whose 850 million speakers make it the most spoken language in the world. The ethnic and linguistic diversity of the Indian civilisation, meanwhile, is as broad as that of the whole of Europe. India's national identity is a combination of cultures, religions, races and tongues. Although Hindi is the primary official language and English the subsidiary official language, there are 22 recognised languages and around 1600 dialects spoken.

- Social structures. Chinese society derives from the same basic root and has had a traditional structure. There was no defined dividing line between the elite and the masses, and social mobility was possible and common. The inhabitants of India, however, belong to thousands of castes establishing hierarchically ordered groups. Each person has a fixed place in the social order, which they keep for life.

- Religious influences. Traditionally, the Chinese have been relatively free from religious influences. Taoism and Buddhism have exercised a certain influence, but it is Confucianism that has had the most profound and lasting effect on Chinese society. Confucianism promotes harmony through moral principles at all levels of human relationships, particularly as regards family and nation. Consequently, a collectivist social order has been created as well as an agnostic attitude toward the supernatural. In contrast, religion has dominated life in India for over 4,000 years. Indian society has been structured mainly by Hinduism, which is based on rituals, castes, a pantheon of gods and reincarnation. Today, Hinduism is practised by over $80 \%$ of the population, and is considered to be the most ancient living religion in the world.

These cultural characteristics are present in the business world and translate into a series of practices and customs that the executives of foreign companies must take into account when doing business with their Chinese and Indian counterparts (Table I). 
Table I. Practices and customs for negotiations in China and India

\begin{tabular}{|c|c|}
\hline \multicolumn{2}{|c|}{ Convergent practices and customs } \\
\hline \multicolumn{2}{|c|}{ Reserved business practices, hierarchical relationships and a highly formal style of communication } \\
\hline \multicolumn{2}{|c|}{ Respect for superiors, family commitments, loyalty to friends, sincerity and courtesy } \\
\hline \multicolumn{2}{|c|}{ Natural paternalists; age is highly respected } \\
\hline \multicolumn{2}{|c|}{ Probable avoidance of saying "no" directly, out of respect for guests } \\
\hline \multicolumn{2}{|c|}{ Consciousness of favours received and an ever readiness to reciprocate } \\
\hline \multicolumn{2}{|c|}{$\begin{array}{l}\text { Desire to extend the utmost hospitality to guests; great insistence upon giving and receiving generous gifts, often } \\
\text { refusing the gift several times before accepting }\end{array}$} \\
\hline \multicolumn{2}{|c|}{ Capacity to apologise for any discrepancy or disagreement } \\
\hline \multicolumn{2}{|c|}{ Divergent practices and customs } \\
\hline China & India \\
\hline There is no room for individualism & $\begin{array}{l}\text { Nor in traditional India, although this has been tempered by } \\
\text { foreign influences }\end{array}$ \\
\hline Trust and personal relationships (guanxi) are vital & These are also valued, although to a lesser degree \\
\hline There is a tendency toward a long-term view & There is an increasing tendency toward seeking a quick profit \\
\hline $\begin{array}{l}\text { Silence is used as a sign of respect for the wisdom and } \\
\text { experience of others, and meaning is often expressed } \\
\text { through non-verbal communication }\end{array}$ & $\begin{array}{l}\text { Indians tend to be very talkative when trying to convey } \\
\text { superior knowledge or express personal opinions, meaning } \\
\text { that is it sometimes difficult for them to listen }\end{array}$ \\
\hline Emotions are not shown in public & Emotions are shown in public \\
\hline Staring causes discomfort & It is customary to look at another out of curiosity \\
\hline $\begin{array}{l}\text { The Chinese are quieter and more reserved, especially } \\
\text { when talking of others }\end{array}$ & $\begin{array}{l}\text { There is a tendency to exaggerate affirmations and little sense } \\
\text { of privacy (no hesitation to ask personal questions), plus a } \\
\text { tendency to "wash dirty linen" in public }\end{array}$ \\
\hline $\begin{array}{l}\text { Chinese women are more open and participate in the } \\
\text { professional and business world }\end{array}$ & $\begin{array}{l}\text { Indian women are usually very timid upon introduction, and } \\
\text { many will not even shake hands when invited to do so }\end{array}$ \\
\hline There is less experience of modern legal systems & $\begin{array}{l}\text { Like Westerners, Indians expect to resolve disputes through } \\
\text { legal action }\end{array}$ \\
\hline $\begin{array}{l}\text { Values are based on human sentiments and not on } \\
\text { religion, and there are fewer restrictions in terms of } \\
\text { eating and drinking }\end{array}$ & $\begin{array}{l}\text { Values are based on religion, and there are greater restrictions } \\
\text { in terms of eating and drinking (menus are usually vegetarian, } \\
\text { and Hindus do not eat beef, as they view cows as sacred } \\
\text { animals) }\end{array}$ \\
\hline $\begin{array}{l}\text { Upon greeting, they lower their eyes and make a slight } \\
\text { bow }\end{array}$ & Upon greeting, they bow with their hands together \\
\hline
\end{tabular}

Source: Based on Bhasin (2007)

\subsection{Other key success factors in China and India}

As well as their adaptation to cultural differences, the success of foreign companies in China and India also involves other considerations: for example, targeting the flourishing middle-class consumers, forging local relationships, benefiting from global networks and working out a flexible exit strategy could all be useful recommendations for both markets (Adams, 2007). When investing in India, it is wise to seek advice, even when entering alongside a local partner. In China, as well as the need to adapt to local preferences and legislation, there is also a lot of competition from both foreign multinationals and domestic Chinese companies. 


\section{Entry modes in China and India}

The legislative framework for regulating foreign investments in China is sprawling and subject to change. Legislation has been constantly changing ever since China joined the World Trade Organisation (WTO) in December 2001. Although there are several regulations concerning foreign investment, the most important law in this respect is the Catalogue for the Guidance of Foreign Investment Industries, the fourth edition of which came into effect in December 2007. It applies to all investment projects involving foreign capital, which are classified into three categories: encouraged, restricted and prohibited.

In India, on the other hand, there are two main laws: the Foreign Exchange Management Act of 1999, which regulates the entry of foreign capital into the country, and the Companies Act of 1956 (amended in 2006), which governs the activity of the businesses set up. However, the procedure to authorise foreign investments remains slow and, in many cases, restrictive (Athreye and Kapur, 2001). Three Indian bodies gain importance in this process of entry into the country: the Reserve Bank of India (RBI), the Secretariat for Industrial Assistance (SIA) and the Foreign Investment Promotion Board (FIPB). Any entry into India as a foreign entity will require the approval of the RBI, and if the activity requires an industrial licence the SIA and/or FIPB must be informed or grant approval according to the entry method chosen.

India is woefully lacking in infrastructures, as the need greatly outweighs the country's capacity for their development (Chen and Warren, 2008). Like the Chinese government years before, in 2000 the Indian authorities promoted Special Economic Zones (SEZs) that were equipped with highly developed infrastructures and in which the tax burden was lessened. The aim was to create a competitive international environment for exports and FDI. Not only did these SEZs imply a desire for greater growth on the overseas market and the domestic Indian market, they also created new liberalisation measures. Unlike other countries, such as China, the main driving force behind their creation - and thus their final owner - is a private investor. However, it must be stressed that 
these SEZs do not allow the free importation of components and raw materials, while the Chinese zones did (Kalish, 2006).

With regard to the entry modes used by foreign companies, these are rather similar in both countries. In China, the most widely used methods are as follows (Claver and Quer, 2005): a representative office (without independent legal standing), which is the most suitable method for initially setting up; a joint venture (which could be based on shares in capital or on a contract between partners); and a foreign wholly-owned subsidiary (which is being increasingly used, as previously stated).

The options are very similar in India, although recent years have seen an increase in entries using technical collaboration agreements (Chakraborty and Nunnenkamp, 2008). The geographical diversity of the country, the complexity of its distribution systems and the need, which is sometimes perceived, for continuous control over operations are factors that must also be taken into consideration. If the choice is made to establish an Indian entity, then the regulatory and fiscal treatment is the same as for companies whose capital is entirely local.

\section{Business opportunities}

Given the enormous urbanisation process taking place in China, architecture is a sector in which it is becoming increasingly common to hire foreign architects and engineers. In India, residential construction is also experiencing major growth as a result of social changes and changing habits. The rising demand for housing is linked to the increasing purchasing power enjoyed by the Indian middle classes, which translates into the possibility of accessing lasting consumer goods. Therefore, the automobile industry is another booming sector.

Huge economic growth and increasing foreign investment have led to a fundamental change in China's industrial make-up, converting the country into one of the world's great factories. As a result, industrial goods are one of the sectors offering the greatest possibilities. Particularly worthy of mention are the vehicle components demanded by the major production centres set up by General 
Motors, Volkswagen and Renault in areas such as Shanghai. Other sectors with potential include machinery and capital goods, farming equipment, railways, airports, urban infrastructure and construction materials. Nevertheless, restructuring policies in the telecommunications sector and the drive for innovation will be key to carrying out new projects in the future. In India, a market renowned for its great growth potential is the ICT sector, which currently accounts for approximately $5 \%$ of GDP.

The huge scale of the infrastructure projects being undertaken by China is opening up opportunities not only in design and construction but also for administrative concessions and the management of thereof ${ }^{4}$. In India, both transport and energy infrastructures are sorely deficient, which often restricts development in other sectors and creates a veritable bottleneck. The Indian economy still needs to make major investments in the electrical grid, the modernisation of the rail network, the extension of the road network and the strengthening of urban public services (drinking water, the collection and treatment of solid urban waste, the sewer system, etc.). China has a serious energy shortage problem that causes numerous and frequent power cuts in some areas. Overdependence on oil and the poor quality of coal make renewable energies a field with great potential.

Consumer goods are also particularly relevant in China. Among the most interesting products are lighting devices, furniture, cosmetics, clothing and footwear. In India, there are many difficulties with retail distribution given that foreign investment is only permitted up to $51 \%$ for single brands (the rest is prohibited). Yet for its conditions in terms of costs and access to raw materials, the Indian market appears to be especially primed for investment in textiles, clothing and footwear.

The banking sector is another area in which there is still a great deal of ground to be covered. In accordance with the commitments undertaken by China following its entry into the WTO, as of 2006 foreign banks may operate in the local currency and several are already positioning 
themselves. This sector is also somewhat restricted in India, although the number of established foreign banks is on the rise.

In India, other sectors in which investment would be advisable are biotechnology (benefiting from the country's highly qualified professionals), health tourism (thanks to the quality of services and professionals together with reduced costs), mining (there are huge reserves and thus possibilities for extraction) and food processing.

Finally, growth is forecast in the tourism sector. China has many destinations with great potential and appeal, although it lacks the experience and resources to develop them. The 2004 signing of the Authorised Destination Status agreement between China and the EU to streamline procedures for tourist visas to Europe has increased European opportunities as a destination to attract the emerging flow of high-earning Chinese tourists. It has been calculated that in 2020 China will be the leading world tourist destination and that some 100 million Chinese will travel abroad, making it also the fourth largest outbound tourist country. In India, in the meantime, tourists have almost doubled in numbers since 2000 and this figure is expected to reach 16 million by 2010 .

\section{Conclusions}

In light of the above, it is worth asking several questions: how far will the development of these two emerging economies go? Will they be able to maintain this rate of growth? Are we witnessing the birth of two authentic economic superpowers that will head up the world economic order in the $21^{\text {st }}$ century?

In theory, both countries already enjoy a series of medium- and long-term advantages (Bustelo, 2008). In the case of China, these advantages are its high level of integration in the world economy, its good physical infrastructures, a development model that generates a lot of employment, and relative macroeconomic stability. In the case of India, these are its "demographic dividend" (which it is expected to hold for at least a further 20 years), its outstanding positioning in ICT services, its booming private business sector and an environmental situation that is less critical 
than China's. Nevertheless, this is just one side of the coin. The other shows a series of future challenges that could become insurmountable obstacles for the progress of the dragon and the elephant. These challenges mean overcoming bottlenecks, past legacies and the negative consequences of such heady growth over a short period of time.

Starting with China, the government's priorities in recent years have run along the following broad lines: maintaining political and social stability, progressing with reforms arising from its entry into the WTO, reorganising state-owned companies and seeking a more balanced growth that avoids a series of threats (inflation, bottlenecks caused by increasing energy dependence and excess production capacity). To prevent its economy from overheating, China must redirect its development patterns away from investment and export and toward domestic consumption. This requires a reduction in the huge rate of private saving, which will in turn depend upon the progress made in the fields of health and pensions. It is disadvantaged by the progressive ageing of its population. The Chinese Communist Party has outlined two priorities for the near future: the need for a "harmonious society" that generates wealth with greater equality, and a "scientific approach to development" that balances growth with environmental sustainability.

In short, China still has some way to go. Its "socialist market economy", as the Chinese themselves describe it, or its "capitalism with Chinese characteristics", as it has also been dubbed, consists of a political system in which the supremacy of the Communist Party is undisputed but with a prevailing economic system in which market forces are increasingly exerted. This model permits the regime to be legitimised thanks to individual prosperity, without it losing its essence as a result. According to Chinese theorists, this phenomenon fits within the "initial stage of socialism" and is only transitional: those who get rich first will pull the rest up until they reach a common prosperity.

India, on the other hand, must also overcome a series of obstacles in order to maintain its growth. The first difficulty is the sectorial make-up of its economy, with a high concentration of employment within the agricultural sector and an oversized service sector (Zaballa, 2006). Retail 
distribution, which is still reserved for small businesses, is one of the reforms pending, as its liberalisation would introduce major economies and efficiencies in the distribution system. The industrial sector shows great potential for growth but is highly constrained by a governmental measure that limits investment in certain production activities, practically restricting these to the status of handicrafts in order to promote employment. The Indian economic environment is still more favourable to small businesses than to large-scale manufacturing plants, which constitutes an obstacle for attracting FDI. However, this situation may begin to change in the future because of two reasons: fewer restrictions in India, which may encourage the growth of its companies, and rising wages along the Chinese coastal areas, which, along with the revaluation of its currency, may increase production costs and cause production capacity to move to other, cheaper countries, such as India (Kalish, 2006).

The second great structural problem facing India is the aforementioned insufficiency of its infrastructures (Zaballa, 2006). This lack of development is the result of scant public investment and a somewhat crude regulatory framework that prevents the entry of private investment. Other issues that need to be addressed for India's economic development include further embracing the privatisation of public companies (there is still resistance to privatising the profit-making firms), the reform of the financial system (a large part of banking is in the hands of the public sector and is subsequently backward and inefficient due to the lack of competition) and labour reforms (India's labour laws are diffuse and antiquated; furthermore, alongside the informal labour market where anything goes, there is another more regulated and rigid labour market with powerful unions and major government intervention).

As well as overcoming all of these challenges in order to extend their journey along the path of growth, China and India pose another question for the future: to what extent are we facing two complementary emerging economies that could form alliances to counterbalance the powerful traditional economies? In other words, is what some people have already dubbed "Chindia" something feasible or is it, rather, a myth? Until recently, relationships between China and India 
have not been particularly friendly. China has maintained political and military ties with Pakistan, a country with which India has been at war and they are still at loggerheads over Kashmir. Yet, despite this, glimmers of an improvement in relationships between the two have recently begun to emerge.

China is the world's great factory, while India has become the world's back office. Nevertheless, this idea that China supplies the hardware and India the software is too simplistic a view of their global roles (Kalish, 2006). Although their respective strengths in manufacturing and services are undisputed, they are not complementary skills. On the contrary, China and India are instead moving towards similar objectives. On the one hand, they are stepping up competition within the same industries. India does not wish to cede the world's intensive manufacturing market to the Chinese labour force and is even advocating a "Chinese model", as the Indian service sector does not have the capacity to generate all the new jobs the country requires. At the same time, China and India are mutually trading and reciprocally investing: Chinese products are becoming increasingly common in India, while Indian software companies are expanding rapidly in China. Thus in the future, rather than close cooperation, we can probably expect fierce competition between the two countries (The Economist, 2006).

With regard to the emerging power of China and India, we cannot neglect to mention the international acquisitions recently being made by some of their companies, converting them into major multinationals (Quer et al., 2008). This is the case for Chinese firms: Lenovo (PC division of the North American IBM), TCL (mobile division of French firm Alcatel) and Nanjing Automotive (British car manufacturer MG Rover), and Indian firms: Dr. Reddy (German pharmaceutical Betapharm), Tata (car brands Land Rover and Jaguar, plus steel company Corus in the UK) and Infosys (technological consultants Axon, also from the UK). Perhaps these acquisitions are just the tip of the iceberg, heralding an emerging phenomenon of greater magnitude that will bring changes to the hegemony enjoyed throughout the $20^{\text {th }}$ century by the European, North American and Japanese multinationals. 


\section{References}

Adams, J. (2007), "Investing in opportunity”, Families in Business, January/February, pp. 47-48.

Athreye, S. and Kapur, S. (2001), "Private foreign investment in India: Pain or panacea?", The World Economy, Vol. 24 No. 3, pp. 399-424.

Bhasin, B.B. (2007), "Succeeding in China: cultural adjustments for Indian businesses", Cross Cultural Management: An International Journal, Vol. 14 No. 1, pp. 43-53.

Bustelo, P. (2008), "España ante el auge económico de China e India”, Boletín Económico de ICE, No. 2937, pp. 103115.

Chakraborty, C. and Nunnenkamp, P. (2008), "Economic reforms, FDI, and economic growth in India: A sector level analysis", World Development, Vol. 36 No. 7, pp. 1192-1212.

Chen, A. and Warren, J. (2008), "Paving the path for India's growth”, Far Eastern Economic Review, Vol. 171 No. 2 , pp. 8-14.

Claver, E. and Quer, D. (2005), “Choice of market entry mode in China: the influence of firm-specific factors", Journal of General Management, Vol. 30 No. 3, pp. 51-70.

Ernst \& Young (2008), European Attractiveness Survey 2008, Ernst \& Young, available at: http://www.ey.com Huang, Y. (2008), “The next Asian miracle”, Foreign Policy, July-August.

Kalish, I. (2006), China and India: The reality beyond the hype, Deloitte, available at: http://www.deloitte.com

KPMG (2008), Global Corporate Capital Flows, 2008/9 to 2013/14. A study of the investment intentions of companies in 15 countries around the world, KPMG, available at http://www.kpmg.com

Meredith, R. (2007), The Elephant and the Dragon: The Rise of China and India and What It Means for All of Us, W.W. Norton, New York, NY.

Nobrega, W. (2008), “Why India will beat China”, Business Week, July.

Peng, M.W., Wang, D.Y.L. and Jiang, Y. (2008), “An institution-based view of international business strategy: a focus on emerging economies", Journal of International Business Studies, Vol. 39 No. 5, pp. 920-936.

PriceWaterhouseCoopers (2008), 11th Annual Global CEO Survey, PriceWaterhouseCoopers, available at: http://www.pwc.com

Quer, D., Claver, E. and Rienda, L. (2008), "China's outward foreign direct investment: Driving factors, theoretical background and strategic implications", 34th EIBA Annual Conference, Tallinn, Estonia.

The Economist (2006), "The myth of Chindia", The Economist, November.

UNCTAD (2008), World Investment Report 2008. Transnational Corporations, and the Infrastructure Challenge, United Nations Conference on Trade and Development, New York and Geneva.

Winters, L.A. and Yusuf, S. (2006), "Introduction: dancing with giants”, in Winters, L.A. and Yusuf, S. (Eds.), Dancing with Giants: China, India and the Global Economy, World Bank and Institute of Policy Studies, Washington DC and Singapore.

WTO (2008), International Trade Statistics 2008, World Trade Organization, Geneva.

Zaballa, J.J. (2006), "Reflexiones en torno al pasado, presente y futuro de la economía India”, in Bustelo, P., Cacho, L. and Zaballa, J.J. (Eds.), La Presencia Española en Países de Fuerte Crecimiento: China e India, Círculo de Empresarios, Madrid.

Zheng, P. (2009), “A comparison of FDI determinants in China and India”, Thunderbird International Business Review, Vol. 51 No. 3, pp. 263-279. 


\section{Endnotes}

${ }^{1}$ In fact, signs of the erosion of the role of these interpersonal relationships are already beginning to be observed: these relationships are necessary but not sufficient for company profitability and, over recent years, subsidiaries that are fully foreign owned are increasingly beginning to be used as a method of entry into China, as opposed to the traditional joint ventures with local partners.

${ }^{2}$ For example, Indian ports currently have a lower capacity than Chinese ports for receiving huge cargo ships.

${ }^{3}$ The result is an education model riddled with paradoxes, which combines an illiteracy rate of $34 \%$ with major university training that places India second only to the US in the number of English-speaking scientists and has led to estimates that by 2035 some $50 \%$ of the world's English-speaking engineers will be Indian.

${ }^{4}$ One of the most impressive projects is the Three Gorges dam along the Yangtze river, which is intended to improve conditions along the middle and lower reaches of the river, allowing flood control and improvements to fluvial navigation. This monumental work (the largest dam in the world) will leave 19 cities and 326 towns and villages under water, affecting over 1,900,000 people and submersing some $630 \mathrm{~km}^{2}$ of Chinese territory. 